\title{
CURRENT APPLICATIONS OF ARTIFICIAL INTELLIGENCE IN TOURISM AND HOSPITALITY
}

\author{
Sonja Zlatanov ${ }^{1, *}$, \\ Jovan Popesku²
}

${ }^{1}$ Business School of Applied Studies, Blace, Serbia

${ }^{2}$ Singidunum University,

Belgrade, Serbia
Correspondence:

Sonja Zlatanov

e-mail:

sonja.zlatanov@gmail.com

\begin{abstract}
:
The revolution brought about with the development of ICTs has caused dramatic changes in tourism and hospitality industry. The Travel 2.0 websites characterized by sharing information freely have been prevailing for some time now and are paving the way for the use of even more sophisticated intelligent systems in tourism and hospitality. Considering the complexity of the travel-related decision making process, intelligent systems and tourism fit in perfectly. Service automation, artificial intelligence and robots have provided tourism companies and organizations with vast new opportunities. Artificial intelligence has already been adopted to some extent in various parts of tourism industry, however, the scientific literature on the subject continues to be scarce. This paper intends to continue the discussion on the artificial intelligence applications in tourism which has just started recently, thus providing much needed scientific view of the subject.
\end{abstract}

\section{Keywords:}

Intelligent systems, chatbots, robots, AI empowered travel bots, digital travel assistants.

\section{INTRODUCTION}

The importance of information in tourism industry has been well documented [1] - [5]. Accordingly, wide adoption of Information and communication technologies (ICTs) in tourism sector was well expected [6], [7]. The acceptance of ICTs brought about extensive changes [8], [9] and a whole new variety of threats and opportunities for tourism companies and organizations. ICTs allow tourists to find, customize and purchase tourism products easily, and they support the globalization of the tourism industry by providing tools for developing, managing and distributing tourism services worldwide [10]. Incorporation of ICTs allows tourism companies and organizations to take advantage of intranets in order to reorganize internal processes, extranets in order to develop transactions with trusted partners, and the Internet in order to easily communicate with all the stakeholders [11]. Use of ICTs allows for combining customer-relationship management and supply chain management into a single source that facilitates a variety of operations - product selection, ordering, fulfillment, tracking, payment and reporting, which are all performed with one easy-to-use tool [12]. 
Evolution of Internet websites into applications that encourage and initiate participation and collaboration among users, known as Web 2.0 applications, have led to the "informatization" of the entire tourism value chain [13] and the development of the concept of Travel 2.0 [14] - [16], that is, internet sites that allow tourists to publicly express their opinion about any travel-related content [17]. These applications have been prevailing for some time now when it comes to the use of Internet by the tourists, and are paving the way for the use of even more sophisticated intelligent systems in tourism industry [18], [19].

\section{THE CONCEPT OF ARTIFICIAL INTELLIGENCE}

Artificial intelligence is increasingly becoming part of our everyday lives [20], [21]. What differentiates intelligent systems from the not intelligent ones is their ability to understand the situation, to acquire and retain knowledge and to conclude based on the previous experiences, and thus be able to quickly and successfully respond to a new situation [22]. Generally, there are two main characteristics of intelligent systems [19]: their ability to sense the environment and their ability to learn from actions in order to maximize success in achieving particular objectives. Robots, artificial intelligence and service automation are widely used in variety of different sectors [23]. Considering the complexity of the travelrelated decision making process, intelligent systems and tourism fit in perfectly. By collecting and processing information about the personal needs of the users, they can facilitate the decision making process and greatly influence tourists' information search. Accordingly, artificial intelligence has already been adopted to some extent in various parts of tourism industry [24] - [26]. Even though the concept of artificial intelligence was introduced by Alan Turing in 1936 [27], and there have been proofs of successful use of artificial intelligence in travel industry at the very beginning of the century [28], the scientific literature on the use of artificial intelligence in tourism industry continues to be scarce. It must be noted that there seems to be an increase in the number of the scientific papers published on the subject in the last two years. It may have something to do with the fact that in 2017 the largest industry intelligence platform providing media, insights and marketing to key sectors of travel, Skift, identified artificial intelligence as a megatrend in tourism industry [29]. This paper intends to continue the discussion on the subject and offers some current ap- plications of artificial intelligence in tourism sector, thus providing much needed scientific view of the subject.

There are two kinds of artificial intelligence systems - pure digital ones and digital-physical hybrids that are usually called robots [30]. Both of the systems are used in different parts of tourism and hospitality industry. When it comes to the pure digital artificial intelligence systems, examples include online check-in systems and mobile boarding passes available in airline industry [23], however, the greatest changes in tourism and hospitality were brought about with the development of different types of chatbots.

\section{USE OF CHATBOTS IN TOURISM AND HOSPITALITY}

Chatbots controlled by artificial intelligence play a very important role in tourism industry. The term "chatbot" is coined from words "chat" and "robot", thus undoubtedly explaining their purpose. Chatbots are essentially computer programs that stimulate a human conversation using natural language [31]. The first chatbot called ELIZA was developed in 1966 [32] and was developed to trick its users by making them believe that they were having a conversation with a real human being [33]. Chatbots have evolved to a great extent since the introduction of the first model and their main fields of use are in retail, customer services, decision making support, state of the art payment systems and online community building [34].

Since chatbots have proven themselves worthy of investment and have shown tremendous growth and market potential, their use in tourism industry increased accordingly. Tourists' need for reliable sources of information is constantly increasing, so travel chatbots are designed to help fulfill those needs and requirements. Travel chatbots are enhancing travel experience as they guide tourists through each and every aspect of their trip, from booking to general travel advice [35]. Depending on the platform they are incorporated in, as well as on their level of sophistication and ability to recommend, there are three different types of travel chatbots: customer service bots, Facebook chatbots and AI empowered travel bots [36].

\section{Customer service travel bots}

Customer service travel bots are the most basic type of chatbots which are incorporated in the travel companies' websites. These bots simply use the list of 
previously determined automated answers and are therefore limited to only helping users navigate the website, without being able to help them with booking. Review of scientific literature and web-based resources showed that there were more customer service travel bots available a couple of years ago than today. It seems as if the travel companies realized the downsides of the insufficiently developed chatbots, and have therefore decided to eliminate them from their websites. These companies include Booking.com, On the Beach and Tap Portugal. However, there are also those who continue using customer service travel bots, such as Copa Airlines, [37] Amtrak [38] and Air New Zealand [39].

\section{Facebook chatbots}

Chatbots incorporated in Facebook Messenger offer far more possibilities for the tourists. Besides simply helping them navigate a certain page, these chatbots are more interactive and can actually help users with booking through a two-way conversation. Even though the users have to put in the same data as they would by booking the trip by themselves, it seems that Facebook chatbots are achieving good results when it comes to users' satisfaction and are proving to be a good investment. In 2018 there were 300,000 active chatbots on Facebook Messenger, which is three times as many as the year prior [40]. One of the most successful Facebook chatbots is Expedia's chatbot [41]. In order to start communicating with Expedia via their chatbot, the users just need to log in to their Facebook accounts and visit Expedia's page [42], and the chat window will pop up automatically. There is one restriction when it comes to the Expedia chatbot compared to the services normally provided by Expedia, and it is that the chatbot can only help users with booking a hotel or managing their trip, but cannot offer services in search of flights, cruises nor cars.

Another example of a well implemented Facebook chatbot is the Skyscanner chatbot [43]. The distinctive features of this chatbot are offering the cheapest destinations from the nearest airport, as well as categorizing flights in cheapest, shortest and best. In addition, in case the tourist just wants some inspiration, he or she can type "anywhere", and the chatbot will return some interesting suggestions. Kayak Facebook chatbot [44] offers its services for fights, hotels, rental cars, activities and trip updates, which probably makes it the most comprehensive chatbot out there. It also has a memory of previous conversations and uses Kayak search history for personalization. Skyscanner and Kayak chatbots are not only available for Facebook Messenger users, but for Slack, Amazon Alexa, Skype and Google Assistant as well. Most of the travel companies with chatbots available are either airline companies or travel search engines. One of the rare cases of tourist board with Facebook chatbot is Faroe Island tourist board. Besides being available on their official Facebook page, users can also start communication with Faroe Island chatbot on their official website via Facebook Messenger extension [45].

\section{AI empowered travel bots}

These chatbots are somewhat different from the previous two groups. Even though they still rely on instant messaging in order to communicate with the users, what differentiates them from the previously mentioned chatbots is their ability to make recommendations. They manage to do it with the help of certain algorithms and access to information, as well as connection with other apps. KLM Royal Dutch Airlines is a good example of a chatbot that went one step further than the ones already mentioned. Besides having Facebook Messenger chatbot offering its help to tourists, this company added one more interesting feature: their chatbot, called BB, can help tourists pack for their trip [46]. It just needs simple information such as the destination, the date and the trip length, and it will tell them everything they need to pack. This feature is available on Google Home Assistant.

Another example is Hello Hipmunk, a virtual travel agent which offers a plethora of services aimed at helping users plan their trip and book all parts of it [47]. However, the most distinguished feature offered by Hello Hipmunk is combining of tourists' emails and calendar information in order to create personalized travel recommendations. It can also build an itinerary for the user's trip and share it with others, such as family or colleagues. It can be accessed on Facebook Messenger and Skype.

There is also HelloGBye travel assistant aimed at frequent fliers and small businesses [48]. The difference between HelloGBuy travel assistant and other ones is the fact that it is an individual app, currently available to IOS users only. However, even though downloading an app, especially the one that is not free, is an obstacle for some users, this app is claimed to be able to address travel requests involving not only one, but 
multiple people, with a detailed flight and hotel itinerary in under 30 seconds, thus making up for the troubles caused to a certain extent.

Last but not least example of AI empowered travel bots is called Sam [49]. Like many other virtual travel assistants, it can be used by an individual user, however, its most important features are more useful for frequent fliers and business travelers. First of all, Sam can help users book their flights, and then it will automatically integrate all the trips in a useful itinerary. If anything arises, such as bad weather forecast, Sam will inform the user of it in order to help him or her pack better. In addition, it will offer to organize the transport to the airport by connecting with local services approved by the traveler's organization. Immediately after landing, Sam already has the information on the baggage claim the traveler should go to, and it can also inform traveler's family members about the safe flight. In addition, it can offers travel guide of the destination and it will be in touch with the traveler throughout the whole trip, informing him or her about bad traffic and delayed flights for example. All these features are enabled by integrating with other apps, such as Avis, Uber and Google Maps. Considering the complexity of this travel assistant, it is an app that needs to be downloaded, and is available for both IOS and Android users.

\section{USE OF ROBOTS IN TOURISM AND HOSPITALITY}

Robots are intelligent physical devices [50] with a certain degree of autonomy, mobility, and sensory capabilities that allow them to perform intended tasks without a human intervention [26], [51]. The least sophisticated industrial robots have been used in tourism and hospitality sector for at least 50 years in different production processes, such as food preparation. As the level of autonomy of robots increases, as well as their ability of social interaction, there are professional service robots and personal service robots, both developed around two decades ago [26] and being further developed on a daily basis. Professional service robots in tourism and hospitality include room cleaning robots [26], self-check-in kiosks and automated border control gates available at many airports, conveyor belt restaurants which are frequent in major cities [23], as well as many others which will be presented below. Personal service robots are the ones used by individuals for noncommercial tasks and will therefore not be further investigated in this paper.
The number of professional service robots used in tourism and hospitality increases every day, as well as their complexity. For example, nowadays there is a robotic suitcase available, which makes traveling a lot easier. It has the ability to follow its owner by itself and avoid any obstacles, thus eliminating the need to carry the suitcase [52]. Robots are being introduced as travel agents [53], as well as airport security [54]. In 2014 a restaurant in China introduced robot waiters [55]. The following year there were testing of the robotic hotel information agents [56], and in 2016, robots were introduced as servers in hotels. A robot server was built and programmed to deliver extra towels, toothpaste or other necessities to the guest rooms [57]. The hotel staff is required in order to introduce the room number on the robot's touch screen, after that the robot uses elevator to go to the designated room. The only way of communicating these robots were capable of was through typed messages that appeared on their screens.

The next step for robots in hospitality industry was a fully automated hotel that opened its doors to visitors. Henn-na hotel in Japan [58] is the world's first hotel staffed exclusively by robots. Robots speaking multiple languages greet and help the customers at the front desk, with one of them being a dinosaur. There are robotic arms which are in charge of storing guests' luggage, and the rooms are excessed by facial recognition systems. This may seem a little over the top, however, this hotel is not the only one introducing robots to all the different positions available in hotels, it is merely the only one using robots exclusively. For example, Hilton Hotel in McLean, Virginia, introduced Connie, robotic concierge that helps guests get around the hotel, answers routine questions about services, and will perhaps one day be able to translate inquiries for guests and staff [59]. Connie is able to interact with visitors by using speech recognition technology in order to respond to their queries. In addition, it also learns from each interaction, meaning the more it is used, the better its responses will become. In addition, there are two Chinese Marriott hotels that have also introduced facial recognition technology to check-in, while Japan Airlines is investigating this idea as well [60].

\section{CONCLUSION}

The revolution brought about with the development of ICTs has caused dramatic changes in tourism and hospitality industry. Service automation, artificial intelligence and robots have provided tourism companies 
and organizations with vast new opportunities. Artificial intelligence is a new form of intelligence which has the ability to synthesize several different ideas simultaneously [34]. It is able to respond to questions and provide valuable information to customers. Modern tourists are more demanding than ever, expecting almost immediate responses on online platforms, and artificial intelligence allows businesses to deliver response times that would be impossible for humans. In addition, chatbots and AI empowered travel bots enable personalization of the tourism offer, as well as improvement of operations and increase of productivity while delivering consistent product quality. However, one of the main downsides of using robots in tourism and hospitality is the lack of personalized service [57], which is one of the most important characteristic of the sector. Artificial intelligence is still not that widespread in tourism sector, but it is expected to be used more often in the future in order to increase the quality of the products and services. This paper relied on scientific journals and web-based resources in order to try to continue the discussion on artificial intelligence applications in tourism which has just started recently. The paper presented numerous applications, however, it only scratched the surface of the subject which is gaining more importance on a daily basis and is being further developed at a very fast pace.

\section{REFERENCES}

[1] U. Gretzel, "Intelligent systems in tourism: A social science perspective", Annals of tourism research, vol. 38, no. 3, pp. 757-779, 2011.

[2] D. Shanker. (May 2008). ICT and tourism: Challenges and opportunities. Presented at Conference on Tourism in India-Challenges Ahead, [Online]. Available: http://dspace.iimk.ac.in/bitstream/han dle/2259/185/?sequence $=1$.

[3] E. Ortega and B. Rodriguez, "Information at tourism destinations. Importance and cross-cultural differences between international and domestic tourists", Journal of Business Research, vol 60, no. 2, pp. 146-152, 2007.

[4] U. Gretzel, Y. Yuan and D. Fesenmaier, "Preparing for the new economadvertising strategies and change in destination marketing organizations", Journal of Travel Research, vol. 39, pp. 146 -156, 2000.

[5] D. Buhalis, "Strategic use of information technologies in the tourism industry", Tourism management, vol. 19, no. 5, pp. 409-421, 1998.
[6] R. Law, D. Buhalis and C. Cobanoglu, "Progress on information and communication technologies in hospitality and tourism", International Journal of Contemporary Hospitality Management, vol. 26, no. 5, pp. 727-750, 2014.

[7] C. Koo, U. Gretzel, W. C. Hunter and N. Chung, "The role of IT in tourism", Asia Pacific Journal of Information Systems, vol. 25, no. 1, pp. 99-104, 2015.

[8] D. Buhalis and R. Law, "Progress in information technology and tourism management: 20 years on and 10 years after the Internet-The state of eTourism research", Tourism management, vol. 29, no. 4, pp. 609-623, 2008.

[9] Z. Xiang, V. P. Magnini and D. R. Fesenmaier, "Information technology and consumer behavior in travel and tourism: Insights from travel planning using the internet", Journal of Retailing and Consumer Services, vol. 22, pp. 244-249, 2015.

[10] D. Buhalis and P. O'Connor, "Information communication technology revolutionizing tourism", Tourism recreation research, vol. 30 , no. 3 , pp. 7-16, 2005.

[11] D. Buhalis, eTourism: Information technology for strategic tourism management. Pearson Education, 2003.

[12] A. Bethapudi, "The role of ICT in tourism industry", Journal of Applied Economics and Business, vol. 1, no. 4, pp. 67-79, 2013.

[13] H. Werthner and F. Ricci, "E-commerce and tourism", Communications of the ACM, vol. 47 , no. 12 , pp. 101-105, 2004.

[14] S. Oklobdžija and J. Popesku, "The link between digital media and making travel choices", Marketing, vol. 48, no. 2, pp. 75-85, 2017.

[15] J. Adam, X. Cobos and S. Liu, Travel 2.0: trends in industry awareness and adoption. New York: New York University and PhoCusWright Inc, 2007.

[16] D. Schmallegger and D. Carson, "Blogs in tourism: Changing approaches to information exchange", Journal of vacation marketing, vol. 14, no. 2, pp. 99-110, 2008.

[17] F. Munoz-Leiva, J. Hernández-Méndez and J. Sánchez-Fernández, "Generalising user behaviour in online travel sites through the Travel 2.0 website acceptance model", Online Information Review, vol. 36, no. 6, pp. 879-902, 2012.

[18] R. Law, M. Fuchs and F. Ricci, Information and communication technologies in tourism 2011. Vienna: Springer, 2011.

[19] U. Gretzel, "Intelligent systems in tourism: A social science perspective", Annals of tourism research, vol. 38, no. 3, pp. 757-779, 2011. 
[20] M. I. A. Ferreira, J. S. Sequeira, M. O. Tokhi, E. Kadar and G. S. Virk, A world with robots. Springer, 2015.

[21] F. Riccio, A. Vanzo, V. Mirabella, T. Catorci and D. Nardi, "Enabling Symbiotic Autonomy in ShortTerm Interactions: A User Study",, presented at ICSR 2016, Kansas City, MO, USA, November 1-3, 2016, 78.

[22] I. J. Rudas \& J. Fodor, "Intelligent systems", International Journal of Computers, Communications \& Control, vol. 3, no. 3, 2008.

[23] S. H. Ivanov and C. Webster, "Adoption of robots, artificial intelligence and service automation by travel, tourism and hospitality companies-a costbenefit analysis", presented at Contemporary tourism - traditions and innovations conference, Sofia, Bulgaria, 19- 21 October 2017.

[24] C. M. Kuo, L.C. Chen and C. Y. Tseng, "Investigating an innovative service with hospitality robots", International Journal of Contemporary Hospitality Management, vol. 29, no. 5, pp. 1305-1321, 2017.

[25] S.H. Ivanov, C. Webster and K. Berezina, "Adoption of robots and service automation by tourism and hospitality companies". Revista Turismo \& Desenvolvimento, vol 27, no. 28, pp. 1501-1517, 2017.

[26] J. Murphy, C. Hofacker and U. Gretzel, "Dawning of the age of robots in hospitality and tourism: challenges for teaching and research", European Journal of Tourism Research, vol. 15, pp. 104-111, 2017.

[27] J. Copeland, Artificial intelligence: A philosophical introduction. John Wiley \& Sons, 2015.

[28] C. J. S. C. Burger, M. Dohnal, M. Kathrada and R. Law, "A practitioners guide to time-series methods for tourism demand forecasting - a case study of Durban, South Africa", Tourism management, vol. 22, no. 4, pp. 403-409, 2001.

[29] R. Ali. "The megatrends defining travel in 2017". Skift.com. https://skift.com/2017/01/12/the-megatrends-defining-travel-in-2017/ (accessed March 21, 2019).

[30] R. Geisler, "Artificial intelligence in the travel \& tourism industry adoption and impact", Ph.D. dissertation, School of Business and Economics, 2018.

[31] Y. F. Wang and S. Petrina, "Using learning analytics to understand the design of an intelligent language tutor-Chatbot lucy", IJACSA, vol. 4, no. 11, 2013.

[32] J. Weizenbaum, "Computer power and human reason: From judgment to calculation", Physics Today, vol. 30, p. 68, 1976.

[33] M. Salecha, "Story of Eliza, the first chatbot developed in 1966". Analytics India. https://www. analyticsindiamag.com/story-eliza-first-chatbotdeveloped-1966/ (accessed March 22, 2019).
[34] M. Zsarnoczky, "How does Artificial Intelligence affect the Tourism Industry?", Journal of Management, vol. 31, no. 2, pp. 85-90, 2017.

[35] Newgenapps, "Chatbots in travel". https://www. newgenapps.com/blog/chatbots-in-travel (accessed March 22, 2019).

[36] J. Sheffield, "The ultimate travel bot list". 30 seconds to fly. https://www.30secondstofly.com/ai-software/ultimate-travel-bot-list/ (accessed March 22, 2019).

[37] Copa Airlines, "Service center". https://connectmiles.copaair.com/en/web/guest/ask-ana (accessed March 22, 2019).

[38] Amtrak, "Meet Julie: your virtual assistant". https:// www.amtrak.com/about-julie-amtrak-virtual-travel-assistant (accessed March 22, 2019).

[39] Air New Zealand, "How can we help". https://www. airnewzealand.co.nz/help-support (accessed March 22, 2019).

[40] P. Cooper, "The complete guide to using Facebook messenger bots for business". Hootsuite. https:// blog.hootsuite.com/facebook-messenger-botsguide/ (accessed March 22, 2019).

[41] M. Marques, "Top 3 chatbots that are changing the travel industry". Medium.com. https://medium. com/hijiffy/top-3-chatbots-that-are-changing-thetravel-industry-d325082c50b8 (accessed March 22, 2019).

[42] Facebook, "Expedia". https://www.facebook.com/ expedia/ (accessed March 22, 2019).

[43] Facebook, "Skyscanner". https://www.facebook. com/skyscanner/ (accessed March 22, 2019).

[44] Facebook, "Kayak". https://www.facebook.com/ kayak/ (accessed March 22, 2019).

[45] The Faroe Islands, "Home page". https://www.visitfaroeislands.com/ (accessed March 22, 2019).

[46] KLM, "Meet BB. KLM's smart assistant". https:// bb.klm. com/en (accessed March 22, 2019).

[47] Hello Hipmunk, "Home page". https://www.hipmunk.com/hello (accessed March 22, 2019).

[48] HelloGBuy, "Home page". https://www.hellogbye. $\mathrm{com} /$ (accessed March 22, 2019).

[49] Meet Sam, "Home page". https://www.meetsam. io/\#app_features (accessed March 22, 2019).

[50] Y. Chen and H. Hu, "Internet of intelligent things and robot as a service", Simulation Modelling Practice and Theory, vol. 34, pp. 159-171, 2013.

[51] N. Tan, R. E. Mohan and A. Watanabe, "Toward a framework for robot-inclusive environments", $\mathrm{Au}$ tomation in Construction, vol. 69, pp. 68-78, 2016.

[52] Travelmate, "Travelmate: a fully autonomous suitcase and robot". https://travelmaterobotics.com/ (accessed March 22, 2019). 
[53] Amadeus IT Group. Amadeus' experimental travel agent's assistant using the Pepper robot (Jan. 24, 2017). Accessed: March 23, 2019. [Online video]. Available: https://www.youtube.com/ watch? $\mathrm{v}=\mathrm{NPbH} 6 \mathrm{QI} \mathrm{qFY}$.

[54] Knightscope, “Autonomous security”. https://www. knightscope.com/ (accessed March 22, 2019).

[55] BBC, "China restauran introduces robot waiters”. https://www.bbc.com/news/av/world-asia30460737/china-restaurant-introduces-robot-waiters (accessed March 22, 2019).

[56] Y. Pan, H. Okada, T. Uchiyama and K. Suzuki, "On the reaction to robot's speech in a hotel public space”, International Journal of Social Robotics, vol. 7, no. 5, pp. 911-920, 2015.
[57] H. Martin, "Robots deliver fun with hotel room service orders, and they don't expect a tip". LA Times. https://www.latimes.com/business/la-fi-hotelrobots-20160207-story.html (accessed March 22, 2019).

[58] Henn na Hotel, "Henn Na Hotel General Concept". http://www.h-n-h.jp/en/concept/ (accessed March 22, 2019).

[59] S. Higginbotham, "This robot aims to improve your hotel stay". Fortune.com. http://fortune. com/2016/03/09/hilton-robot-ibm-watson/ (accessed March 22, 2019).

[60] Eye for travel, "Part I: AI, facial recognition and hotel robots march into 2019". https://www.eyefortravel.com/mobile-and-technology/part-i-aifacial-recognition-and-hotel-robots-march-2019 (accessed March 22, 2019). 